\title{
Ethical Issues Arising from Marijuana Use by Nursing Mothers in a Changing Legal and Cultural Context
}

\author{
Jessica Miller ${ }^{1}$ \\ Published online: 3 December 2018 \\ (c) Springer Nature B.V. 2018
}

\begin{abstract}
In the early 2000s, several states legalized marijuana for medicinal uses. Since then, more and more states have either decriminalized or legalized marijuana use for medical or recreational purposes. Federal law has remained unchanged. The statelevel decriminalization of marijuana and the concomitant de-stigmatizing and mainstreaming is likely to lead to greater use among the general population, including among nursing mothers. Marijuana is already one of the most widely used illicit substances among lactating women. There exist few studies demonstrating the effects of marijuana in breast milk on nursing babies. In the present context of a changing legal landscape, shifting cultural beliefs, and the absence of clear professional guidelines, healthcare professionals are faced with ethical questions around how best to support nursing mothers and their babies when marijuana use is a factor. This paper first presents an overview of the law, science, and professional guidelines as they relate to marijuana and breastfeeding. Then, I offer an assessment of the relevant ethical issues providers and their patients may need to navigate.
\end{abstract}

Keywords Breastfeeding $\cdot$ Nursing mother $\cdot$ Marijuana $\cdot$ THC $\cdot$ Ethics $\cdot$ NICU

\section{Introduction}

In the early 2000s, several states legalized marijuana for medicinal uses. Since then, more and more states have either decriminalized or legalized marijuana use for medical or recreational purposes. Federal law has remained unchanged. The state-level decriminalization of marijuana and its concomitant de-stigmatizing and mainstreaming is likely to lead to greater use among the general population, including among nursing mothers. Marijuana is already one of the most widely used illicit substances among lactating women (Hughes et al. 2018). There exist few studies demonstrating the effects of marijuana in breast milk on nursing babies. In the present context of a

Jessica Miller

Jessica.p.miller@maine.edu

1 Department of Philosophy, University of Maine, Orono, ME 04469, USA 
changing legal landscape, shifting cultural beliefs, and the absence of clear professional guidelines, healthcare professionals are faced with ethical questions around how best to support nursing mothers and their babies when marijuana use is a factor. This paper first presents an overview of the law, science, and professional guidelines as they relate to marijuana and breastfeeding. Then, it offers an assessment of the relevant ethical issues providers and their patients may need to navigate.

\section{The Law}

Thirty-two states and the District of Columbia have legalized the use of marijuana for the treatment of symptoms related to a variety of conditions including arthritis, multiple sclerosis, cancer, and HIV/AIDs. California was the first state to legalize medical marijuana in 1996. In 2012, Colorado and Washington became the first states to vote to legalize marijuana for recreational purposes. Since then, seven states and the District of Columbia have passed laws allowing for the personal possession and consumption of cannabis by adults. These states are Alaska, California, Maine, Massachusetts, Nevada, Oregon, and Vermont. In November 2018, medical marijuana was legalized in Missouri and Utah, while Michigan became the first Midwestern state to legalize recreational use of marijuana. Generally, although not uniformly, states have adopted policies supporting a state-controlled market where consumers can buy marijuana for personal use from a safe, regulated source.

Compared to changes in state law, federal law relating to marijuana has been stable. Federal US drug policy was established in 1970 by the Controlled Substances Act (CSA) (21 U.S.C. § 811), which does not recognize the difference between medical and recreational use of marijuana. Federal laws are generally applied only against persons who possess, cultivate, or distribute large quantities of cannabis. Beginning in 2013, under the Obama administration, the federal government did not enforce federal laws in states where marijuana is legal and appropriate regulations are in place. A January 2018 memo to the Justice Department by then Attorney General Jeff Sessions rescinded all previous guidance on marijuana enforcement, leading to speculation that federal enforcement priorities may change under the Trump administration (Sessions 2018). However, Sessions' memo, while noting that "marijuana is a dangerous drug and that marijuana activity is a serious crime," reaffirmed the importance of prosecutorial discretion and weighing of all relevant considerations. In April 2018, in response to concerned questioning by senators whose states have legalized marijuana, Sessions affirmed before the Senate Appropriations Committee that "Our priorities are fentanyl, heroin, methamphetamine, cocaine. ... People are dying by massive amounts as a result of those drugs. We have very few, almost zero, virtually zero small marijuana cases. But if they are a big deal and illegally acting and violating federal law, our agents may work that case" (Sessions 2018). In March 2018, Rohrabacher-Blumenauer (first passed in 2014, then known as Rohrabacher-Farr), an amendment to the annual appropriations bill that prohibits the Department of Justice from using federal funds to interfere with states' medical marijuana programs, was extended for six months. In short, federal law and enforcement policy remains stable. 
The changing legal landscape both reflects and affects public attitudes. Marijuana is the most used drug in the US: in 2015, 13.2\% of Americans had used marijuana in the past month and $8.3 \%$ of American in the past year (Azofeifa et al. 2016). Among women, $11 \%$ had used marijuana in the past year and $6.2 \%$ had used the drug in the past month. A majority of the population favors decriminalization (53\%), up from 12\% in 1969 (Doherty et al. 2015). The advent of "medical marijuana" has contributed to the perception among all age groups that marijuana use is a low risk activity.

Marijuana is the most commonly used recreational drug during pregnancy (Martin et al. 2015). From 2002 to 2014, the prevalence of self-reported, past-month marijuana use among US adult pregnant women increased from $2.4 \%$ to $3.9 \%$ (Brown et al. 2017). In a recent California study, marijuana use among pregnant females increased from 4\% to 7\% from 2009 to 2016 (Young-Wolff et al. 2017). The same study found higher rates of marijuana use among pregnant females (22\% of pregnant females under 18 , and $19 \%$ of pregnant females ages 18-24) by using toxicology reports, suggesting that self-reported numbers are likely to be artificially low (Young-Wolff et al. 2017). An estimated 84\% of marijuana users continue use during lactation (Eidelman and Schanler 2012). Millennials currently account for the vast majority of United States births (Metz and Stickrath 2015) and at 70\%, are significantly more likely than other generations to support marijuana legalization (Geiger 2018). Fifty-three percent of marijuana users are millennials (Ingraham 2017). This is the new context in which healthcare providers find themselves.

It is common for women who use any illicit substance in the prenatal or perinatal period to fear losing custody of their newborns and/or their other children, and being subject to criminal justice consequences for their substance use (Stone 2015). Reporting requirements differ from state to state, and it is important for healthcare professionals to know what the law requires in their jurisdiction. Typically, reporting laws in states which allow marijuana for medical or recreational purposes fall under more general abuse and neglect reporting requirements. For example, reporting is usually mandatory when a newborn suffers from withdrawal symptoms that require a higher level of care than normal to treat, and any time a child experiences adverse effects from a parent's substance use, legal or illegal (Martin 2017).

Marijuana using women who feel judged or threatened may be discouraged from seeking comprehensive care during and after their pregnancies. Generally, this is not an outcome that enhances their well-being. By understanding the law and their own institutional policies, providers can alleviate patients' unnecessary worries while being transparent about their medical concerns and their legal and ethical duty to report in some situations. This can help build trusting relationships, even in those cases where a duty to report might exist. Staff may also have an unclear sense of their personal liability and professional responsibilities. For example, NICU nurses who administer expressed breast milk to infants via bottles or feeding tubes may worry about being legally implicated should evidence emerge that severe neurodevelopmental consequences result from THC in breast milk. Having up-to-date legal guidance, reflected in clear hospital policies, and disseminated via sound educational strategies, is key to enhancing provider-patient relationships and minimizing negative health outcomes. 
In the past several years, rapid changes in state law, growing inconsistency between federal and state laws, and shifts in rhetoric from Washington have contributed to the uncertain environment in which healthcare providers practice. They require guidance from local counsel on current state law, which in almost all situations will determine actual enforcement. In states where marijuana use, either for recreational or medicinal purposes, is legal, attorneys will typically defer to clinical judgment on questions about maternal marijuana use during lactation. Healthcare professionals have a responsibility to understand the legal context with a view to reassuring worried patients, colleagues, and staff when possible, and transparently explaining reporting requirements when necessary.

\section{The Science}

Despite the prevalence of marijuana use by lactating women, studies of its health effects on this population and on neonatal outcomes are scarce. Among the unanswered questions are the amount of THC (tetrahydrocannabinol, the chemical compound in cannabis that stimulates a psychoactive response) in breast milk of mothers who use marijuana, its absorption and metabolism by infants, and any resulting health effects. The challenges to designing and implementing such studies are varied. Of course, inherent challenges exist whenever research on human subjects includes vulnerable populations such as pregnant women, human fetuses, and neonates (Department of Health and Human Services 1983, 2009). And in the United States, because it is a Schedule I drug, researchers have extremely limited access to research-graded cannabis (Cousijn et al. 2018).

When those hurdles are cleared, other challenges arise. It is difficult to isolate the effects of marijuana from those related to concurrent use of other substances (tobacco, alcohol, other illicit drugs). Tobacco in particular is often used concomitantly with marijuana in rolled cigarettes. The presence of contaminants in marijuana (fungi, pesticides, heavy metals) can also affect results. Maternal marijuana use while breastfeeding is associated with factors that may independently affect mothers, fetuses, and newborns. These include prenatal family history, maternal cognitive ability, mental illnesses, and socioeconomic status (Van der Pol et al. 2013). The reliance on self-report of use of illicit substances can make it difficult to connect actual use with outcomes.

A 2016 systematic review and meta-analysis on neonatal outcomes concluded that "the association between maternal marijuana use and adverse outcomes appears attributable to concomitant tobacco use and other confounding factors" (Conner et al. 2016). However, a study published in 2017, while concurring that maternal marijuana use was not associated with adverse outcomes such as small for gestational age, preterm birth, and hypertensive disorders, concluded that it is associated with an increased risk of neonatal morbidity (Metz et al. 2017). Further spurring the need for more study is the fact that quantities of THC in contemporary marijuana products are much higher than in the 1980s, when the initial round of findings on THC in breast milk were obtained (ElSohly et al. 2016). Researchers call for more clarity on any links between marijuana use and adverse health outcomes, as well as 
good data on the long-term consequences of prenatal marijuana exposure (Metz and Stickrath 2015).

Existing research on the effects of maternal marijuana use on nursing infants are of limited generalizability and suffer from shortcomings in study design. For example, studies focus on heavy chronic users, have small sample sizes, use single-items measures, and/or draw from uncontrolled random screenings resulting in little control for demographic differences between substance-using pregnant women and their non-substance using peers. The pharmacokinetics, direct physiological effects and longer-term health effects of cannabis further depend on the individual and mode of administration, leading some researchers to call not only for more study of the possible benefits of marijuana use, but the recognition that effects may differ between and even within individuals (Cousijn et al. 2018). Limited data suggests that active components of marijuana are excreted into breast milk in small quantities, and some researchers have posited theoretical risks, the most significant being altered neurodevelopment with chronic, heavy use of marijuana by breastfeeding mothers (Lockwood 2017; Jaques et al. 2014). Key gaps in knowledge include the amount of THC in breast milk, the length of time THC remains in breast milk, the effects of breast milk containing THC on infants, and when it is safe to resume breastfeeding after use of marijuana. Some researchers are also now calling for an equal emphasis on possible therapeutic benefits. In an opinion issued in 2017, ACOG concluded that "There are insufficient data to evaluate the effects of marijuana use on infants during lactation and breastfeeding" (Committee on Obstetric Practice 2017).

\section{Clinical Guidance}

The American College of Obstetrics and Gynecology, American Academy of Pediatrics, and the Academy of Breastfeeding Medicine, agree that in the absence of good data on health effects on the infant, marijuana use during lactation should be discouraged. Professional medical organizations recommend counseling on the risks of marijuana use, along with advice to abstain while breastfeeding, and referral to substance abuse support services when appropriate. The American Society of Addiction Medicine's guidelines are representative: "Women who are pregnant or contemplating pregnancy should be encouraged to discontinue marijuana use" (American Society of Addiction Medicine 2015).

Thomas W. Hale, RPh, PhD, a Professor of Pediatrics at Texas Tech University School of Medicine, and the Executive Director of the InfantRisk Center, is the author of Medications and Mothers' Milk, a widely consulted reference for evaluating medication use in breastfeeding mothers. The 2017 guide classifies marijuana lactation risk category as L4-Limited Data-possibly hazardous and recommends strongly discouraging marijuana use during lactation (Hale and Rowe 2017). In a January 2018 interview, Hale acknowledges that "the breast milk data is old and was poorly done years ago" (Hale 2018). Hale is currently conducting a study to determine how much marijuana is excreted into breast milk with standardized dosages in Colorado where recreational marijuana has been decriminalized since 2012. Hale commented that 
It's too soon to know, but I'm thinking the relative infant dose is going to be small and the oral absorption poor. This study, we hope, is just the beginning, as much more needs done, such as oral dosing studies, blood level studies in mom and infant, different metabolites and forms of THC, etc. ... We may this year change the lactation risk category for marijuana if the levels in milk are exceedingly low as I suspect (Hale 2018).

In 2016, the CDC published recommendations on screening and management of substance abuse in the perinatal period with a view to improving provider-patient interactions (Wright et al. 2016). The report emphasized that healthcare professionals should conduct verbal screening for substance abuse at the first prenatal visit in all pregnant women and continue screening throughout the pregnancy for women at higher risk. The $\mathrm{CDC}$ also encourages providers to use open-ended and nonjudgmental questions. The LactMed database, part of the National Library of Medicine's TOXNET system, a Web-based collection of resources covering toxicology, chemical safety, and environmental health, contains information on drugs and other chemicals that breastfeeding mothers may be exposed to. It concludes, "Because breastfeeding can mitigate some of the effects of smoking and little evidence of serious infant harm has been seen, it appears preferable to encourage mothers who use cannabis to continue breastfeeding and reducing or abstaining from cannabis use while minimizing infant exposure to the smoke" (Toxicology Data Network 2017).

In addition to the guidance provided by professional organizations and the federal government, clinicians in states where recreational marijuana has been decriminalized have access to materials produced by state departments of public health and similar agencies. In Colorado, for example, state guidance aligns with the AAP recommendations and focuses on nonjudgmentally informing patients about the potential risks of marijuana use while breastfeeding, emphasizing that there is no known safe amount of marijuana use, and encouraging support and referral for cessation (Colorado Department of Public Health and Environment 2017). Easily understood talking points are provided, such as, "THC is stored in body fat. A baby's brain and body are made with a lot of fat. Since your baby's brain and body may store THC for a long time, you should not use marijuana while you are breastfeeding." Similarly, Nevada guidance emphasizes neutral language in the context of uncertain science, while emphasizing the benefits of breast milk for babies (Nevada Division of Public and Behavioral Health 2017; State of Nevada 2017).

There are very are few studies on actual clinical practice. A 2014 study of lactation consultants in New England, based on a convenience sample with five closeended questions posed to 74 attendees at a state-level lactation consultant conference found a wide range of practices. The largest group (44\%) indicated that their recommendations to patients depend on the severity of marijuana use. Forty-four percent counsel that breastfeeding continue during concomitant marijuana use because they believe the benefits of breastfeeding likely outweigh the burdens of THC ingestion to the baby, and $15 \%$ recommend that mothers who use any marijuana should stop breastfeeding altogether (Bergeria and Heil 2015; Salisbury 2017). An unpublished 2016 survey of a small number of medical doctors, naturopaths, osteopaths, nurse practitioners, midwives, and lactation consultants in private practice conducted in 
Washington state concluded that "Most participants agree that the benefits of breastfeeding may outweigh the potential risks of light maternal recreational marijuana use. However, nearly all participants discourage marijuana use during breastfeeding due to lack of research about the effects of use on children" (Salisbury 2017).

Clinical recommendations on marijuana use for pregnant and lactating women share some similarities with those for alcohol use, in that they both emphasize negative health effects on the fetus or baby. Emily Oster has argued that there is at best a shaky evidence base for the abstinence-only discourse around safe levels of alcohol consumption during pregnancy, especially in the second and third trimesters (Oster 2014, p. 39). Similarly, conflicting public information contributes to distorted perceptions of the risk of antidepressant use during pregnancy, leading to lower medication adherence for pregnant women with mood disorders (Misri et al. 2013, p. 1183). Extreme conservatism in the case of caffeine and alcohol use on the part of healthcare providers exceeds the evidentiary basis while ignoring other factors and may be exaggerated by paternalistic attitudes towards women.

\section{Ethical Issues}

A lack of good data, vague clinical recommendations, rapid cultural shifts, and a complex legal and regulatory environment leave healthcare professionals and patients with questions and concerns that make ethical decision making around marijuana and breastfeeding even more complicated. This section explores some of the ethical concerns that arise, especially for nurses, in the specific context of feeding infants in the NICU and makes recommendations for practices and policies which support allowing mothers who use marijuana to make an informed choice as to how their babies may be fed, by themselves or by others.

Screening recommendations differ among professional settings, and providers may become aware of marijuana use by breastfeeding mothers via screening, toxicology testing, or patient self-report. Beneficence requires balancing risks and benefits and working to promote good health outcomes for the patient, and screening can help promote this good by encouraging disclosure of use of a substance that may be risky for mother and breastfed child. It is important to ascertain frequency and amount of use, information which toxicology reports cannot provide. Self-reports are likely to be less reliable to the extent that the patient feels judged or threatened, so paying attention to language and tone is important. Leading off with "the righting reflex", i.e., warnings about marijuana use in the context of breastfeeding, and admonitions to stop immediately, is likely to minimize the chances of developing the kind of rapport that is necessary for working with the patient to promote beneficence (Shapiro et al. 2013). Not only that, but as we will see below, it may not be clear which course of action is "right" until more information is obtained. 
It is important to try to understand why a nursing mother is using marijuana. ${ }^{1}$ This relates to respect for patient autonomy. When the child is the patient, it relates to respecting the autonomy of the patient's legal representative. Autonomy requires not only freedom from controlling influences, but also agency. Undue influence, coercion, and manipulation are rhetorical strategies that can be agency-defeating. Women who use marijuana while breastfeeding may believe that they are acting in a way that is, on balance, best for themselves and their baby, either directly or indirectly. The point of establishing a joint understanding about the role of marijuana use in the patient's life is not merely, or even necessarily, greater efficacy in getting her to stop using. Understanding the mother's beliefs, values, and goals, and how marijuana use fits into those, is respectful of her personhood, and her right to make healthcare decisions for herself and her child. Because values are often inchoate, conflicting, or just not transparent to the patient, it may be helpful to think of this as an autonomy-enhancing dialogue. Providers should approach nursing patients who use marijuana with an awareness that, depending on the particular context, there may be a range of "right" paths forward.

It is also worth reflecting on the different cultures from which healthcare professionals and some medical marijuana-using patients hail. Health care providers are working from a context in which there is, as of yet, no such thing as "medical marijuana." Medical marijuana is "recommended," not "prescribed" or "dispensed." Hospital formularies in most states do not carry marijuana due to federal law and lack of FDA approval, and many hospital policies either forbid it outright, or only allow patient self-administration of cannabis products. Even those hospitals that allow staff to administer medical marijuana require charting it as "continuation of therapy" rather than "medication" (Durkin 2017). But these subtleties are lost on many patients, for whom marijuana looks an awful lot like any other prescribed treatment. So, when nursing mothers use "medical marijuana" to alleviate symptoms of anxiety, depression, or one of the many other diseases which marijuana is thought to help control, their thought process regarding continued use while nursing may be no different from deciding whether the benefits of taking prescription medications such as antidepressants outweigh the risks to their babies.

For some women, use of marijuana occurs in the context of a broader personal and cultural turn to complementary therapies, including herbal supplements. They might see it as an organic alternative, more affordable and less dangerous, than traditional medicine. These women put marijuana in the same risk category as the fenugreek, blessed thistle, and fennel they use to stimulate milk supply, herbs of unknown efficacy and safety, also unregulated by the FDA. Far from viewing it as a danger, some women use marijuana specifically to help with breastfeeding, for example, to stimulate their appetite, or to relax them and assist the let-down reflex. Others view marijuana as an indirect support for breastfeeding and mothering. They

\footnotetext{
1 This section includes representative comments by posters who identified as breastfeeding mothers on public websites. These were located by the author using search engine queries such as "pot and nursing" and "smoking weed while breastfeeding." Additional details are not provided because they may identify the authors.
} 
might use it to alleviate pain after delivery, believing it to be safer and less subject to abuse than prescription painkillers. They might be aware that high stress can interfere with milk production and is associated with early weaning, so they use marijuana to keep calm during a challenging adjustment to breastfeeding or in a stressful family setting. They may even believe the psychotic effects are directly beneficial to the baby, for example, to help the baby sleep. This information provides an opportunity for clinical education around safer ways to promote relaxation and sleep.

Because marijuana and alcohol are increasingly perceived as similar in their effects, social acceptability, and legal status, women who use marijuana might believe that the advice to wait two hours after drinking a glass of wine or beer before nursing, also applies to marijuana. Of course, marijuana stays in the body for longer than alcohol and it has not been determined what, if any, waiting period might reduce harm. It is important to educate patients regarding differences between metabolization of alcohol and marijuana so that when they make choices, they are informed ones. Again, this enhances patient autonomy.

Understanding the role marijuana use plays in a nursing mother's life can point providers to alternatives for managing her symptoms that are less risky to herself and to her baby. However, for some women, it may be the case that continued use of marijuana is, while nursing, on balance less risky than using formula. In those situations, healthcare professionals can help their patients practice harm reduction strategies, for example, avoiding smoking near the baby and minimizing use. The Academy of Breastfeeding Medicine recommends that clinicians counsel patients to "carefully weigh the risks of initiation and continuation of breastfeeding while using marijuana with the risks of not breastfeeding while also considering the wide range of occasional, to regular medical, to heavy exposure to marijuana" (Reece-Stremtan et al. 2015).

So far, this section has emphasized gaps in patient appreciation of risks and knowledge of alternatives to marijuana. While it is common to focus on gaps in patient knowledge and lapses in patient reasoning, clinical uncertainty has recently gained increased attention (Han et al. 2011). Health care providers can find it challenging to accept uncertainty, but avoiding addressing uncertainty has been associated with detrimental effects on patients (Simpkin and Schwartzstein 2016). Withholding the ambiguous state of current evidence can lead to premature closure of important conversations, foreclosing opportunities for mutual education. Worse, it may create openings for unconscious biases to influence attitudes of providers. The absence of a strong evidence base for recommending for or against breastfeeding of neonates in the NICU when breast milk may contain THC should be made manifest and included as part of the overall process of shared decision-making. In this way, uncertainty can enhance the mother's autonomy, which is especially important for a subgroup of patients already subject to stigmatization and lack of parenting confidence. Admitting that there is not enough evidence as yet to make a strong clinical recommendation can also increase patient trust in providers.

Moreover, a growing literature suggests that medical decision-making of healthcare professionals is subject to certain context-specific cognitive biases. All humans use heuristic strategies (decisional short cuts), which can lead to systematic errors in judgment. In the present context, a loss/gain framing bias-the tendency to 
view losses as larger than gains-may lead clinicians to overvalue the avoidance of harms from THC in breast milk relative to the gain in continuing to breast feed over substituting with formula (Blumenthal-Barby and Krieger 2015). To counteract the cognitive bias that may overemphasize the potential harms of breast milk containing amounts of THC, a review of American Academy of Pediatrics (AAP) Policy Statement on Breastfeeding and the Use of Human Milk offers a countervailing reminder of the strong evidence base for the benefits of breast milk over formula (Eidelman and Schanler 2012). Exclusive breastfeeding significantly decreases rates of obesity, diabetes, celiac disease, childhood leukemia, gastrointestinal tract infections, necrotizing enterocolitus, sudden infant death syndrome, and infant mortality. Exclusive breastfeeding is also correlated with significant positive effects on long-term neurodevelopment. Other advantages to breastfeeding include health benefits to the lactating women, economic benefits to her household, and psychological and emotional benefits for both mother and child. For all of these reasons, the AAP, the American College of Obstetricians and Gynecologists (ACOG), and the Association of Women's Health, Obstetric and Neonatal Nurses (AWHONN) are among the many healthcare organizations that recommend exclusive breastfeeding for newborns as the normative standard for infant feeding and nutrition and deem it an important public health goal.

Despite the uniformity and strength of this recommendation in the U.S., among infants born in 2013, 20\% did not breastfeed at all, about half were breastfeeding at 6 months, and most (about 70\%) were not breastfeeding at 1 year (U.S. Government, National Center for Chronic Disease Prevention 2016). The literature shows that professional support increases initiation and continuation of breastfeeding. Moreover, perception about infant nutritional benefits is a key factor in determining whether a mother initiates and continues breastfeeding. Some researchers recommend that health professionals explicitly enumerate the risks of formula feeding in addition to the benefits of breastfeeding, because otherwise women gain the impression that they are of about equal value (Radzyminski and Callister 2016). Healthcare professionals should reframe their attitude towards maternal marijuana use to adequately take into consideration these factors, especially when low rates of breastfeeding are already a public health concern.

The NICU is a setting where maternal use of marijuana is especially fraught. Individual hospitals may test all mothers, mothers who self-report drug use, have tested positive for drug use in the past, present with preterm labor, and/or those with no prenatal history. Infant signs of withdrawal such as irritability, shakiness, or prolonged distress may also trigger testing. After a THC-positive test, some nurses are reluctant to personally administer expressed breast milk, even when they otherwise support the mother in establishing breastfeeding. To some nurses, the right of a mother to breastfeed her own infant should be trumped by their own right to refuse to engage in administering potentially harmful substance to their patient. A refusal to administer breast milk in these situations feels like a natural extension of the nurse's duty to protect the health of very vulnerable infants in the NICU.

These nursing concerns in the NICU setting should be addressed with the larger legal, clinical, and ethical context of maternal marijuana use in mind. Neonatal nurses are also charged with promoting breastfeeding: "Neonatal nurses have 
a responsibility to facilitate, through support and evidence-based information, the provision of human milk and breastfeeding. It is essential to ensure that infants receive human milk through hospital discharge and that mothers have the opportunity to reach their personal breastfeeding goals" (Spatz and Edwards 2016). As discussed previously, the risks to breastfed infants of maternal marijuana use are unknown, while the benefits of breastfeeding over formula feeding are well established. Because marijuana can linger in urine for up to thirty days, and even longer for casual users, a single positive THC result provides no indication of how recently the mother used marijuana, or of how heavy the mother's marijuana use is, nor does it offer information about the mother's perception of how marijuana might contribute to her own mental and physical well-being. Nurses in the NICU should be encouraged to frame their ethical concerns in the context of both their responsibility to promote the health of the patient, and in the context of shared decision making and family-centered care. It is important for nurses to understand that by substituting formula, they are withholding a benefit_-breast milk—and, more importantly, potentially sabotaging the establishment or continuation of a successful nursing bond between mother and child.

Mothers whose infants are in the NICU are already vulnerable to post-traumatic stress, feelings of inadequacy, depression, and anxiety (Obeidat et al. 2009) The attitudes and behaviors of healthcare professionals can have a disproportionately large impact on nursing mothers, despite comprising a fraction of the time these women will spend breastfeeding their child. For mothers who experience premature delivery, providing their own milk may feel like the only way they can care for their child, can help them connect, and can minimize guilt (Rossman et al. 2013). Nurses themselves may be concerned about personal legal liability in areas where marijuana in any form is illegal, or they may fear running afoul of reporting requirements. Hospital administration should clarify reporting requirements for nurses and notify them of institutional protection for employees from personal liability.

Some hospitals address these concerns by allowing individual nurses to opt out, substituting formula for breast milk when infants cannot nurse. However, the unintended negative consequences of such a policy should be carefully considered. First is the aforementioned negative impact on the establishment of breastfeeding for this already vulnerable mother-infant dyad. Second is the patient and mother experience of inconsistency that occurs when feedings depend on which nurse is on duty in the unit. Third is the potential violation of the mother's right to determine how her baby is fed, traditionally an ethically protected space for parents to exercise their judgment based on their own values and the child's best interests. Ethicists have long argued that parents should make decisions about the medical care of their children based on the best interest standard, which includes the emotional, social, and spiritual well-being of the child (Kopelman 2007). The evidence that feeding breast milk with THC violates a reasonable conception of the infant's best interests is not strong enough to override the mother's rights.

Especially in states where marijuana is legal, fairness dictates consistency in treating potentially harmful substances in breast milk (Krening and Hanson 2018, p. 47). This includes looking carefully at how marijuana policies differ from those around other legal, but potentially harmful substances such as nicotine, alcohol, 
and even prescribed medications. If hospitals are unwilling to reflect on how breastfeeding policies in the NICU cohere with policies on other potentially harmful substances, such as nicotine, then they do not have good grounds for singling out marijuana. A prohibition on administering breast milk which contains THC must follow from a transparent decision matrix for determining whether the risk of providing mother's own milk (MOM) is outweighed by the benefits for a particualr patient. Management should support nurses who experience distress with education, peer support, and other tools. It may help to emphasize that consistency of care within and across patients has many health and social benefits for patients and family. It can encourage better connections which improve the health of patients. It can allow for the development of trust relationships that lead to better adherence to provider recommendations (in particular, the recommendation to stop using marijuana). And, it can generate feelings of satisfaction in mothers with their hospital experience.

Another strategy is to increase the availability of donor human milk (DHM) to substitute for MOM when nurses decline to use the mother's expressed breast milk. Again, this must be an evidence-based decision where known benefits and risks should be evaluated. Recent studies suggest that the multiple benefits of MOM cannot be generalized to DHM: "In particular, there is lack of fit between preterm MOM and DHM during the early critical post birth window when nutritional and immunomodulatory programming and select organ growth via MOM components are thought to occur" (Meier et al. 2017). Another consideration is the cost of DHM to hospitals, which is much higher than MOM. Given the harm-benefit scenario described at length above, hospitals' investment in DHM clashes with their responsibility to be good stewards of scarce resources. A better hospital investment would be education of NICU staff, patients, and the community.

Some nurses may frame their refusal to administer expressed breast milk after a positive test for THC in terms of conscientious objection. Professional conscientious objection is a refusal to comply with professional obligations as stated by law or institutional rule, by claiming moral or conscientious reasons. Conscientious objections are widely recognized across the profession, including by the Joint Commission and the American Nurses Association (Waller-Wise 2005; American Nurses Association 2015). The most common objections relate to a conflict between the nurse's religious beliefs and abortion, euthanasia, and patient refusal to accept treatment (Toto-Flores et al. 2017). A recent phenomenological study indicates that nurses themselves view conscience as something that allows them to discern right from wrong, and compels them to act accordingly (Lamb et al. 2017). A conscientious objection is different from mere disagreements with patients' or surrogate decision-makers' choices (Lachman 2014). To act against one's own conscience in this sense is to betray one's deepest beliefs and risk one's own integrity.

Despite widespread recognition, conscientious refusal itself is controversial and conceptually contested, not least because health care providers have freely chosen their career, and thus implicitly accept the professional norms which guide it (WestOram and Buyx 2016). Its inclusion in codes of professional ethics creates inherent tension with the primary injunction to place the well-being of patients above one's own personal beliefs (Stahl and Emanuel 2017). The right to conscientious objection is not unqualified. The ANA is clear that, "Conscience-based refusal to participate 
exclude personal preference, prejudice, bias, convenience, or arbitrariness" (American Nurses Association Center for Ethics and Human Rights 2011). Mothers with substance use disorder experience lack of empathy from nurses for their disease, lack of trust from nurses, and the need for separation from their infant due to perceived negative judgment from nurses (Reyre et al. 2014). The refusal to feed expressed MOM to infants in the NICU is most likely related to lack of education, bias, and prejudice. In many cases, education, not conscientious refusal, is the path towards better nurse-mother relationships, and, by extension, better mother-child relationships.

Prior to accepting a staff member's request not to participate in an aspect of a patient's care, the hospital should ascertain whether it is genuine. Fear of being sued, distaste for a procedure, or worries about public disapproval, are not claims of conscience. The hospital should also consider what impact the refusal will have on the patient's well-being, whether the objector's claims are evidence-based, and to what extent conscientious refusal further disadvantages an already disadvantaged patient and family. Women who use marijuana are more likely to be less educated, poor, and use other substances, all additional factors associated with stigmatization. In most cases, a nurse's claim of conscience in this matter should not be honored.

\section{Conclusion}

Changes in state laws and social attitudes governing marijuana use in the past two decades have created a new cultural context for healthcare professionals working with breastfeeding mothers. While decriminalization of marijuana use does not pose the same immediate clinical challenges as, say, the legalization of physician assisted death, it is part of a quickly changing cultural landscape to which clinicians must adapt. Marijuana dispensaries, vape shops, and the smells of pot smoke on city streets are common sights and sounds today when just twenty years ago, most adults associated pot with adolescents, criminals, and Dead Heads. The line between recreational and medical uses of marijuana is malleable and constantly moving, and will likely become less relevant as this drug is increasingly mainstreamed. Breastfeeding women may use marijuana for a variety of recreational, social and health reasons, and, as with alcohol use, companies will likely target them with marijuana-based products. For example, the company Mother and Clone plans to sell "sublingual CBD nano-sprays" in discreet attractive packaging (Mother and Clone 2018). Just as alcohol use, especially wine, has become increasingly common and acceptable in mothering culture in the US., for coping with the stresses of motherhood, socializing on play dates, and lubricating book clubs, so marijuana products are likely to follow.

A variety of factors have contributed to the current scientific lag in understanding the effects of marijuana on breastfeeding mothers and their children. These include federal law, protections governing research on vulnerable populations, and co-occurring substance use. The complex legal situation and gaps in scientific understanding leave clinicians with uncertainties about how best to promote beneficence, nonmaleficence, respect for autonomy, and justice and fairness for mothers and babies in the breatsfeeding context. Because its effects on nursing 
babies are unknown and possibly harmful, nursing mothers should normally be counseled to stop using marijuana, but not without a full understanding of how she views the relationship of marijuana use to her own health and that of her baby. Counseling is likely to be more effective to the extent that healthcare providers approach their patients with nonjudgmental attitudes. They should encourage open discussion, and aim to acquire an understanding of the extent of marijuana use, and of how marijuana use functions in the lives of these women.

But, providers should be honest about the knowledge gap that currently exists, and recognize that there is more at stake than protecting the infant from possible harm. They should encourage the mother's autonomy, respect her right to decide what and how her child is fed, and support maternal-infant bonding by working with her to make her own informed decision. This may include helping her reflect on her values and goals, and how marijuana use meshes-or doesn'twith those. It will require some skills in eliciting personal values and stimulating reflection. Referral to substance disorder treatment, mental health treatment, or to other specialists who can better address the patient's health needs may be indicated. Although this may change with emerging science, at this time, providers should generally not counsel mothers to substitute formula, except in situations of chronic, heavy use, and should be open to the possibility that depending on the nature and extent of use, on balance, if cessation is not an option, breastfeeding may be a better choice for the marijuana-using mother and baby alike.

Legalization and rapid cultural change have created a changed landscape for marijuana use, and nowhere is this more fraught than in the situation of breastfeeding in the NICU. Hospitals and medical practices will need to support their clinical staff by informing them of current local, state, and federal laws, and how they are (or are not) enforced. Staff should be educated on the current state of the medical literature including on implicit bias as it relates to patient substance use and substance use disorder. Healthcare providers should be encouraged to reflect on their own attitudes and behaviors. Hospitals and medical practices should also work to adopt policies that ensure consistency of care. They should also examine existing practices to ensure they produce equal treatment of all patients and families, avoid stigmatization, and optimize health outcomes based on available evidence. Adequate staffing and support are vital for preventing compassion fatigue and burnout, which can lead to judgmental behaviors and suboptimal outcomes in this context. In a changing practice environment, doctors, nurses, patients, and healthcare administrators should prepare themselves for the ethical questions raised by breastfeeding in the context of maternal marijuana use, whether illicit or legal.

\section{Compliance with Ethical Standards}

Conflict of interest The author declares that she has no potential conflicts of interest to disclose.

Ethical Approval This article does not contain any studies with human participants or animals.

Informed Consent There is no informed consent because this article does not contain any studies performed by the author involving human subjects. 


\section{References}

American Nurses Association. (2015). Code of ethics for nurses with interpretive statements: Provision 5.4. https://www.nursingworld.org/practice-policy/nursing-excellence/ethics/code-of-ethics-fornurses/. Accessed 29 Nov 2018.

American Nurses Association Center for Ethics and Human Rights (2011). Non-punitive alcohol and drug treatment for pregnant and breast-feeding women and their exposed children. American Nurses Association Position Statement. https://www.nursingworld.org/ 4af078/globalassets/docs/ ana/ethics/nonpunitivetreatment-pregnantbreastfeedingwomen-sud.pdf. Accessed 29 Nov 2018.

American Society of Addiction Medicine. (2015). Public policy statement on marijuana, cannabinoids, and legalization. http://www.asam.org/docs/default-source/publicy-policy-statements/marijuanacannabinoids-and-legalization-9-21-2015.pdf?sfvrsn=0. Accessed 29 Nov 2018.

Azofeifa, A., Mattson, M. E., Schauer, G., McAfee, T., Grant, A., \& Lyerla, R. (2016). National estimates of marijuana use and related indicators-National survey on drug use and health, United States, 2002-2014. Morbidity and Mortality Weekly Report, 65(11), 1-28.

Bergeria, C. L., \& Heil, S. H. (2015). Surveying lactation professionals regarding marijuana use and breastfeeding. Breastfeeding Medicine, 10(7), 377-380.

Blumenthal-Barby, J. S., \& Krieger, H. (2015). Cognitive biases and heuristics in medical decision making: A critical review using a systematic search strategy. Medical Decision Making, 35(4), 539-557.

Brown, Q. L., Sarvet, A. L., Shmulewitz, D., Martins, S. S., Wall, M. M., \& Hasin, D. S. (2017). Trends in marijuana use among pregnant and no pregnant reproductive-aged women, 2002-2014. Journal of the American Medical Association, 317(2), 207-209.

Centers for Disease Control and Prevention. (2016). Breastfeeding report card, progressing toward national breastfeeding goals. https://www.cdc.gov/breastfeeding/pdf/2016breastfeedingreportca rd.pdf. Accessed 29 Nov 2018.

Colorado Department of Public Health and Environment. (2017). Marijuana pregnancy \& breastfeeding guidance for Colorado health care providers prenatal visits. https://www.colorado.gov/pacific/sites/ default/files/MJ_RMEP_Pregnancy-Breastfeeding-Clinical-Guidelines.pdf. Accessed 29 Nov 2018.

Committee on Obstetric Practice. (2017). Marijuana use during pregnancy and lactation. ACOG Committee Opinion No. 722. October. American College of Obstetricians and Gynecologists. https://www. acog.org/Clinical-Guidance-and-Publications/Committee-Opinions/Committee-on-Obstetric-Pract ice/Marijuana-Use-During-Pregnancy-and-Lactation. Accessed 29 Nov 2018.

Conner, S. N., Bedell, V., Lipsey, K., Macones, G. A., Cahill, A. G., \& Tuuli, M. G. (2016). Maternal marijuana use and adverse neonatal outcomes: A systematic review and meta-analysis. Obstetrics and Gynecology, 128(4), 713-723.

Cousijn, J., Núñez, A. E., \& Filbey, F. M. (2018). Time to acknowledge the mixed effects of cannabis on health: A summary and critical review of the NASEM 2017 report on the health effects of cannabis and cannabinoids. Addiction, 113(5), 958-966.

Doherty C., Alec T., Weisel R. (2015). In debate over legalizing marijuana, disagreement over drug's dangers. Pew Research Center. http://assets.pewresearch.org/wp-content/uploads/sites/5/2015/04/0414-15-Marijuana-release.pdf. Accessed 29 Nov 2018.

Durkin, M. (2017). Medical marijuana... in the hospital? ACP Hospitalist. https://acphospitalist.org/archi ves/2017/01/marijuana-policies-hospital.htm. Accessed 29 Nov 2018.

Eidelman, A., \& Schanler, R. (2012). Breastfeeding and the use of human milk. American Academy of Pediatrics. http://inaap.org/wp-content/uploads/2016/05/AAP-Breastfeeding-and-the-Use-ofHuman-Milk.pdf. Accessed 29 Nov 2018.

ElSohly, M. A., Mehmedic, Z., Foster, S., Gon, C., Chandra, S., \& Church, J. C. (2016). Changes in cannabis potency over the last 2 decades (1995-2014): Analysis of current data in the United States. Biological Psychiatry, 79(7), 613-619.

Geiger, A. (2018). About six-in-ten Americans support marijuana legalization. Pew Research Center. http://www.pewresearch.org/fact-tank/2018/01/05/americans-support-marijuana-legalizati on/. Accessed 29 Nov 2018.

Hale, T. W. (2018). Interview with Dr Hale, author of Medications and Mothers' Milk. https://kellymom. com/bf/can-i-breastfeed/meds/interview-dr-hale/. Accessed 29 Nov 2018.

Hale, T. W., \& Rowe, H. E. (2017). Medications and mothers' milk (17th edn). New York: Springer.

Han, P. K., Klein, W. M., \& Arora, N. K. (2011). Varieties of uncertainty in health care: A conceptual taxonomy. Medical Decision Making, 31(6), 828-838. 
Hughes, A., Lipari, R. N., \& Williams, M. R. (2018). Marijuana use and perceived risk of harm from marijuana use varies within and across states. The CBHSQ Report. https://www.samhsa.gov/data/ sites/default/files/report_2404/ShortReport-2404.html. Accessed 29 Nov 2018.

Ingraham, C. (2017, April 19). 11 charts that show marijuana has truly gone mainstream. Washington Post. https://www.washingtonpost.com/news/wonk/wp/2017/04/19/11-charts-that-show-marijuanahas-truly-gone-mainstream/?utm_term=.20413af14ca3. Accessed 29 Nov 2018.

Jaques, S. C., Kingsbury, A., Henshcke, P., Chomchai, C., Clews, S., Falconer, J., et al. (2014). Cannabis, the pregnant woman and her child: Weeding out the myths. Journal of Perinatology, 34(6), 417-424.

Kopelman, L. M. (2007). Using the best interest standard to decide whether to test children for untreatable, late-onset genetic diseases. Journal of Medicine and Philosophy, 52, 375-394.

Krening, C., \& Hanson, K. (2018). Marijuana-perinatal and legal issues with use during pregnancy. The Journal of Perinatal \& Neonatal Nursing, 32(1), 43-52.

Lachman, V. D. (2014). Conscientious objection in nursing: Definition and criteria for acceptance. $M E D$ SURG Nursing, 23(3), 196.

Lamb, C., Evans, M., Babenko-Mould, Y., Wong, C. A., \& Kirkwood, K. W. (2017). Conscience, conscientious objection, and nursing: A concept analysis. Nursing Ethics. https://doi.org/10.1177/09697 33017700236.

Lockwood, C. J. (2017). Medical marijuana: An oxymoron and a risk to fetuses. Contemporary $O B / G Y N$, $62(3), 6$

Martin, J. (2017). Mandated reporting of marijuana use during pregnancy. Statement regarding mandated reporting of Marijuana use during pregnancy. Maine Office of Child and Family Services. https:// fccamaine.wordpress.com/2017/03/16/mandated-reporting-of-marijuana-use-during-pregnancy/. Accessed 29 Nov 2018.

Martin, C. E., Longinaker, N., Mark, K., Chisolm, M. S., \& Terplan, M. (2015). Recent trends in treatment admission for marijuana use during pregnancy. Journal of Addiction Medicine, 9(2), 99-104.

Meier, P., Patel, A., \& Esquerra-Zwiers, A. (2017). Donor human milk update: Evidence, mechanisms, and priorities for research and practice. The Journal of Pediatrics, 180, 15-21.

Metz, T. D., Allshouse, A. A., Hogue, C. J., et al. (2017). Maternal marijuana use, adverse pregnancy out-comes, and neonatal morbidity. American Journal of Obstetrics and Gynecology, 217(4), 478. e1-478.e8.

Metz, T. D., \& Stickrath, E. H. (2015). Marijuana use in pregnancy and lactation: A review of the evidence. American Journal of Obstetrics and Gynecology, 213(6), 761-778.

Misri, S., Eng, A. B., Abizadeh, J., Blackwell, E., Spidel, A., \& Oberlander, T. F. (2013). Factors impacting decisions to decline or adhere to antidepressant medication in perinatal women with mood and anxiety disorders. Depression \& Anxiety, 30(11), 1133.

Mother and Clone. (2018). Cannabis. https://www.momandclone.com/products. Accessed 29 Nov 2018.

Nevada Division of Public and Behavioral Health. (2017). Marijuana pregnancy and breastfeeding guidance for health care providers. http://dpbh.nv.gov/uploadedFiles/dpbhnvgov/content/Programs/MIP/ Marijuana\%20Pregnancy\%20and\%20Breastfeeding\%20Guidance.pdf. Accessed 29 Nov 2018.

Obeidat, H. M., Bond, E. A., \& Callister, L. C. (2009). The parental experience of having an infant in the newborn intensive care unit. Journal of Perinatal Education, 18(3), 23-29.

Oster, E. (2014). Expecting better. Why the conventional pregnancy wisdom is wrong-and what you really need to know. New York: Penguin Press.

Radzyminski, S., \& Callister, L. C. (2016). Mother's beliefs, attitudes, and decision making related to infant feeding choices. The Journal of Perinatal Education, 25(1), 18.

Reece-Stremtan, S., Marinelli, K. A., \& Academy of Breastfeeding Medicine. (2015). ABM clinical protocol\# 21: Guidelines for breastfeeding and substance use or substance use disorder, revised 2015. Breastfeeding Medicine, 10(3), 135-141.

Reyre, A., Jeannin, R., Larguèche, M., Hirsch, E., Baubet, T., Moro, M. R., et al. (2014). Care andprejudice: moving beyond mistrust in the care relationship with addicted patients. Medicine, Health Careand Philosophy, 17(2), 183-190.

Rossman, B., Kratovil, A. L., Greene, M. M., Engstrom, J. L., \& Meier, P. P. (2013). "I Have Faith in My Milk": The meaning of milk for mothers of very low birth weight infants hospitalized in the neonatal intensive care unit. Journal of Human Lactation, 29(3), 359-365.

Salisbury, K. W. (2017). Medical provider perceptions of breastfeeding women who use recreational marijuana. Master's thesis, University of Washington. https://digital.lib.washington.edu/researchwo 
rks/bitstream/handle/1773/40203/Salisbury_washington_0250O_17145.pdf?sequence=1\&isAll owed=y. Accessed 29 Nov 2018.

Sessions, J. (2018). Memorandum for all United States attorneys, marijuana enforcement. https://www. justice.gov/opa/press-release/file/1022196/download. Accessed 29 Nov 2018.

Shapiro, B., Coffa, D., \& McCance-Katz, E. F. (2013). A primary care approach to substance misuse. American Family Physician, 88(2), 113-121.

Simpkin, A. L., \& Schwartzstein, R. M. (2016). Tolerating uncertainty-the next medical revolution? New England Journal of Medicine, 375(18), 1713-1715.

Spatz, D. L., \& Edwards, T. M. (2016). The use of human milk and breastfeeding in the neonatal intensive care unit: Position statement 3065. Advances in Neonatal Care, 16(4), 254.

Stahl, R. Y., \& Emanuel, E. J. (2017). Physicians, not conscripts-conscientious objection in health care. New England Journal of Medicine, 376(14), 1380-1385.

State of Nevada. (2017). Marijuana pregnancy and breastfeeding guidance for health care providers. http://dpbh.nv.gov/uploadedFiles/dpbhnvgov/content/Programs/MIP/Marijuana\%20Pregnanc y\%20and\%20Breastfeeding\%20Guidance.pdf. Accessed 29 Nov 2018.

Stone, R. (2015). Pregnant women and substance use: Fear, stigma, and barriers to care. Health \& Justice, 3(1), 2.

Toto-Flores, R., Bravo-Agüi, P., Catalán-Gómez, M. V., et al. (2017). Opinions of nurses regarding conscientious objection. Nursing Ethics. https://doi.org/10.1177/0969733017731915.

Toxicology Data Network. (2017). Canabis. Drug Levels and effects: Summary of use during lactation. U.S. National Library of Medicine. http://toxnet.nlm.nih.gov/cgi-bin/sis/search2/r?dbs+lactmed:@ term+@DOCNO+693. Accessed 28 Nov 2018.

U.S. Government, Department of Health and Human Services. (1983). Additional protections for children involved as subjects in research-Department of Health and Human Services. Final rule. Federal Register, 8(48), 9814-9820.

U.S. Government, Department of Health and Human Services. (2009). Code of Federal Regulations, Title 45, Public Welfare, Part 46, Protection of Human Subjects. https://www.hhs.gov/ohrp/regulation s-and-policy/regulations/45-cfr-46/. Accessed 29 Nov 2018.

U.S. Government, National Center for Chronic Disease Prevention. (2016). Breastfeeding report card. https://www.cdc.gov/breastfeeding/pdf/2016breastfeedingreportcard.pdf. Accessed 29 Nov 2018.

Van der Pol, P., Liebregts, N., De Graaf, R., Ten Have, M., Korf, D. J., Van den Brink, W., et al. (2013). Mental health differences between frequent cannabis users with and without dependence and the general population. Addiction, 108(8), 1459-1469.

Waller-Wise, R. (2005). Conscientious objection. Nursing for Women's Health, 9(4), 283-286.

West-Oram, P., \& Buyx, A. (2016). Conscientious objection in healthcare provision: A new dimension. Bioethics, 30(5), 336-343.

Wright, T. E., Terplan, M., Ondersma, S. J., Boyce, C., Yonkers, K., Chang, G., et al. (2016). The role of screening, brief intervention, and referral to treatment in the perinatal period. American Journal of Obstetrics and Gynecology, 215(5), 539-547.

Young-Wolff, K. C., Tucker, L., Alexeeff, S., Armstrong, M. A., Conway, A., Wedsiner, C., et al. (2017). Trends in self-reported and biochemically tested marijuana use among pregnant females in California from 2009-2016. Journal of the American Medical Association, 318(24), 2490-2491. 